\title{
Electrocatalytic enhancement of formic acid oxidation reaction by acetonitrile on well-defined platinum surfaces
}

\author{
Valentín Briega-Martos a , José Solla-Gullón ${ }^{\text {a }}$, Marc T.M. Koper ${ }^{\mathrm{b}}$, Enrique Herrero ${ }^{\text {a, *, }}$ \\ Juan M. Feliu a \\ ${ }^{a}$ Instituto de Electroquímica, Universidad de Alicante, Apdo. 99, E-03080, Alicante, Spain \\ ${ }^{\mathrm{b}}$ Leiden Institute of Chemistry, Leiden University, PO Box 9502, 2300, RA, Leiden, the Netherlands
}

\section{A R T I C L E I N F O}

\section{Article history:}

Received 2 April 2018

Received in revised form

1 November 2018

Accepted 3 November 2018

Available online 5 November 2018

\section{Keywords:}

Formic acid oxidation

Platinum single crystal electrodes

Acetonitrile

Electrocatalysis

\begin{abstract}
A B S T R A C T
The formic acid oxidation reaction has been studied on $\operatorname{Pt}(111), \operatorname{Pt}(100)$ and $\mathrm{Pt}$ nanoparticles with preferential (111) surface structure in $0.1 \mathrm{M} \mathrm{HClO}_{4}$ in the presence of different concentrations of acetonitrile. An electrocatalytic enhancement towards the formic acid oxidation has been observed under these conditions, and it is proposed that this enhancement is due to two different effects of the adsorbed acetonitrile species: a third-body effect which hinders the formation of $\mathrm{CO}$ and a promoting effect of the direct oxidation of formic acid. This promoting effect is structure sensitive. The different enhancement between $\mathrm{Pt}(111)$ and $\mathrm{Pt}(100)$ indicates that the ratio of free Pt sites and sites occupied by adsorbed acetonitrile is important in order to have the better electrocatalytic activity. On-line mass spectrometry (OLEMS) measurements confirmed the preference for the direct oxidation of formic acid to $\mathrm{CO}_{2}$, which is almost complete below $0.3 \mathrm{~V}$ vs. RHE for Pt(111). Finally, chronoamperometric studies confirmed the lower poisoning rate in the presence of acetonitrile but they also pointed out a competition of formed CO for the Pt sites occupied by acetonitrile species. This work constitutes an example of electrocatalytic enhancement by using an organic molecule for surface modification, which is not as common as using metallic adlayers.
\end{abstract}

ㄷ) 2018 Elsevier Ltd. All rights reserved.

\section{Introduction}

The electrochemical oxidation of small organic molecules is an issue of paramount importance in the development of lowtemperature fuel cells technology as a feasible alternative for energy production [1]. Formic acid is the simplest small organic molecule amongst all that are being investigated as possible fuels, and its electrooxidation is considered as a model reaction in electrocatalysis [2]. On platinum surfaces, formic acid oxidation reaction takes place through a mechanism with two parallel pathways, as summarized by Capon and Parsons [3-5]: a direct route involving an active intermediate which immediately gives $\mathrm{CO}_{2}$ as the final product, and a second path that implies the dehydration of formic acid to yield CO (as confirmed by in-situ IR spectroscopy [6-9]), a poisoning intermediate that blocks the surface of the electrocatalyst. This mechanism was experimentally confirmed by

\footnotetext{
* Corresponding author.

E-mail address: herrero@ua.es (E. Herrero).
}

using differential electrochemical mass spectrometry (DEMS) measurements [10]. Adsorbed bidentate formate has been detected as a surface-adsorbed intermediate by ATR-SEIRAS [11-13], although other infrared spectroscopy, DEMS measurements and DFT calculations showed that this species is not the active intermediate $[14,15]$.

Formic acid is a structure-sensitive reaction [8,16-18]. In this sense, studies with single crystal electrodes provide a fundamental knowledge about the interfacial properties in order to understand the electrocatalytic phenomena by allowing a cross-feedback between theory and experiment [19]. In addition, their use, especially of stepped surfaces, can help to elucidate the mechanism of structure-sensitive reactions $[19,20]$. In the case of formic acid oxidation, cyclic voltammetry at high scan rates with single crystal electrodes confirmed that bidentate adsorbed formate is involved in the active path, probably aiding or limiting the adsorption of an additional formate species in the right configuration [21-23].

Amongst all the pure metals, platinum and palladium show the best activity for the oxidation of small organic molecules [4,24]. However, the overpotentials required for having high oxidation 
currents on these metal surfaces are still high and platinum is poisoned by adsorbed CO intermediate [1]. The electrocatalytic performance of a metal electrode can be improved by changing the composition of the surface [25]. Following this idea, the combination of platinum with other metals can form alloys with improved electrocatalytic activities for the oxidation of organic molecules, since the changes in the electronic structure give rise to changes in the surface reactivity. For example, PtRu-colloid based catalysts show an improved performance towards methanol oxidation [26], $\mathrm{PtPb}, \mathrm{PtBi}$ and PtPd nanoparticles are excellent catalysts for the oxidation of formic acid [27-30], while PtSnNi nanoparticles enhance the electrocatalytic activity for ethanol oxidation [31]. The improvement of the electrocatalytic activity of an electrode surface by composition modification can also be achieved by deposition of (sub)monolayer amounts of a metallic adatom [32]. In this sense, electrocatalysis of several organic molecules oxidation reactions using different adatoms has been observed in polycrystalline and well-oriented surfaces and also in nanoparticles with controlled surface structure [33-46]. The use of well-oriented surfaces can be extremely useful for the clarification of the role played by the adatom in the mechanism of these reactions [47]. For the specific case of formic acid oxidation, and considering its dual-path mechanism, electrocatalysis promoted by adatoms can be due to two different effects that can act simultaneously [48]. On one hand, it can be observed that any modification of the metal surface leading to an inhibition of the poison formation results in an improvement of the electrocatalytic activity by increasing the available free sites (the so-called third-body effect). On the other hand, the presence of adatoms can enhance directly the reaction kinetics of the reaction by modification of the electronic structure of the metal. Depending on the used adatom, the particular mechanism of electrocatalysis will be different, leading to differences in the magnitude of the increased oxidation current. For example, the measured current for formic acid oxidation in $\operatorname{Pt}(111)$ is increased by a factor of 40 in the presence of a Bi adlayer [49], while in the case of As adatoms there is an enhancement by a factor 1.5 [50]. These effects have been recently rationalized using a combined experimental and theoretical approach [2,47], which shows that the adatom has retained a partial positive charge upon adsorption. The partial charge, which is proportional to the difference in electronegativity with the Pt, directs the adsorption of formate in the right configuration to yield $\mathrm{CO}_{2}$. The $\mathrm{pH}$ value of the working solution also affects the products that are generated during the formic acid oxidation [51] and therefore a careful selection of the solution $\mathrm{pH}$ in combination with the use of metallic adlayers is a possible strategy for enhancing the rate of formic acid formation.

Metal surfaces can be modified not only by other metallic elements but also by the irreversible adsorption of organic molecules [52-55]. One of the first studied organic molecules that lead to a surface modification of a Pt surface was acetonitrile [52]. Acetonitrile can adsorb irreversibly on Pt from dilute solutions and remain adsorbed without desorption if the potential is not driven to the oxide formation region. In the adsorbed state, acetonitrile can undergo an almost reversible redox process between 0.05 and $0.75 \mathrm{~V}$ vs RHE [52]. Formic acid oxidation reaction was studied in aqueous acid solutions in the presence of acetonitrile and an enhancement of the oxidation current was observed [56,57]. The electrocatalytic effect produced by acetonitrile was explained assuming a thirdbody effect: the organic adsorbates leave sufficient space for the direct oxidation of formic acid, but not for the formation of $\mathrm{CO}$ poison intermediate. In conclusion, adsorbed acetonitrile on the platinum surface can produce an analogous effect to the electrocatalytic improvement carried out by the presence of a metallic adatom adlayer. Formic acid oxidation was also studied in the presence of dimethyl sulfoxide (DMSO), but in this case, it was found that DMSO inhibits this reaction. Additionally, unlike formic acid oxidation reaction, the oxidation of methanol in presence of acetonitrile was inhibited [58]. It is clear then that there is an electrocatalytic effect that depends on the adsorbed organic molecule and on the desired organic molecule oxidation to be electrocatalyzed. The presence of nitromethane can also promote the formic acid oxidation at lower potentials than $0.8 \mathrm{~V}$ vs. RHE, while at higher potentials this reaction gets inhibited [59]. As there are important differences in the electrocatalytic effect produced by acetonitrile and nitromethane, it was proposed that there is not only a third-body effect but also a modification of the electronic properties of the platinum substrate. Following this idea, the types of interaction of acetonitrile and nitromethane would be different, leading therefore to differences in the observed electrocatalysis [59]. It should be highlighted that interfacial water molecules have always an important role in electrocatalytic processes, due to the interaction between the reacting species and water molecules and between water molecules and the surface. All these interactions are present even at very high acetonitrile concentrations [60,61], and thus, the role of water should be always studied when analysing the reaction mechanism.

A more recent example of electrocatalysis carried out by other species different from metallic adatoms consists of using adlayers of carbon or ethylidyne [54], and the results indicate site blocking at low carbon coverages, while at high coverages there is a formation of platinum ensembles which optimize the total oxidation of formic acid at the expense of the surface poison. The influence on the formic acid oxidation of the presence of ethylidene on the surface of Pt nanoparticles, deposited during the ethylene electroreduction and confirmed by surface-enhanced Raman spectroscopy (SERS), has been studied [55,62]. The observed enhancement in the formic acid oxidation current can be attributed to a third-body effect and to a destabilization of the adsorbed $\mathrm{CO}$ poison intermediate. This effect was also studied later for another type of alkylidyne, propylidine, pointing out that the destabilization of adsorbed carbon monoxide is independent of the nature of alkylidyne intermediates [63]. Recently, it has been observed that the presence of several organic impurities such as acrylonitrile, vinyl acetate, acetonitrile, acetamide, pyridine or pyrrole have a promoting effect on the formic acid oxidation on glassy carbon electrodes modified with Pt nanoparticles used in fuel cells [64-66]. This effect was attributed to a third-body effect and a modification of the electronic properties of the platinum surface that stabilizes an adsorption mode of formic acid, making easier the charge transfer during its oxidation.

In order to understand the way in which modification of the surface affects the mechanism of the oxidation reactions and therefore their electrocatalysis, the use of well-defined surfaces can be determinant. In the case of organic surface modifiers, the number of studies with well-defined surfaces is scarce. Morin et al. studied acetonitrile adsorption on Pt single crystals in acid aqueous solution, both in $0.5 \mathrm{M} \mathrm{H}_{2} \mathrm{SO}_{4}$ and $0.1 \mathrm{M} \mathrm{HClO}_{4}$, by using pure electrochemical measurements and in-situ infrared spectroscopy $[67,68]$. They observed that the adsorption and surface reactivity of acetonitrile is very sensitive to the structure of the different surfaces. The FTIR studies allowed to propose the formation of a reduced intermediate with a $\mathrm{C}-\mathrm{N}$ double bond tilted with respect to the surface plane [68]. However, there are no studies about the electrocatalytic improvement of the formic acid oxidation reaction by adsorbed acetonitrile in well-defined platinum surfaces.

In this work, a study of the formic acid oxidation enhancement by acetonitrile on platinum single-crystal is presented for the first time, in order to clarify the electrocatalytic mechanism in the presence of this organic molecule. Cyclic voltammetry studies with $\mathrm{Pt}(111)$ and $\mathrm{Pt}(100)$ electrodes are performed in combination with 
on-line mass spectrometry measurements in order to confirm that the complete oxidation to $\mathrm{CO}_{2}$ is taking place. Finally, chronoamperometric measurements for the studied basal planes and cyclic voltammetry experiments for platinum nanoparticles with (111) preferred orientation have been carried out in order to study the performance of formic acid oxidation reaction near to practical fuel cell conditions in the presence of acetonitrile.

\section{Experimental}

Cyclic voltammetry experiments were performed in a threeelectrode electrochemical glass cell following the general procedure described in Ref. [69]. Platinum single crystal working electrodes were prepared from small Pt beads with a diameter of ca. $2 \mathrm{~mm}$, as described by Clavilier et al. [70]. The well-oriented surfaces used in this work are $\mathrm{Pt}(111)$ and $\mathrm{Pt}(100)$ basal planes. Prior each measurement, the working electrode was cleaned by flameannealing in a propane-oxygen flame, and after that, it was cooled down in an $\mathrm{Ar} / \mathrm{H}_{2}$ (3:1) atmosphere in order to avoid surface oxidation and ensuring the nominal topographies and the lowest amount of defects [71]. Then the electrode was transferred to the electrochemical cell protected by an ultrapure water drop saturated with this gas mixture. The counter electrode was a platinum coiled wire in the cases of Pt single crystal experiments, while for the Pt nanoparticles supported on a glassy carbon electrode the counter electrode was a gold coiled wire. In both cases, the counter electrode was cleaned by flame annealing. The reference electrode used in all cases was a reversible hydrogen electrode (RHE). An EG\&G PARC signal generator and eDAQ EA161 potentiostat with an Edaq e-corder recording system was used for the electrochemical measurements, except in the case of the in-situ registration of the cyclic voltammetry during the on-line mass spectrometry experiments, in which an Iviumstat potentiostat was employed.

Platinum nanoparticles with preferential octahedral and tetrahedral shape $\left(\right.$ PtNP $\left._{\text {tetra }}\right)$ were synthesized by a colloidal method using polyacrylate as a capping agent and a $10^{-4} \mathrm{M} \mathrm{H}_{2} \mathrm{PtCl}_{6}$ aqueous aged solution as the metallic precursor [72]. The concentration ratio of $\mathrm{H}_{2} \mathrm{PtCl}_{6}$ to polyacrylate was (1:5). The suspension $\mathrm{pH}$ was adjusted to 7 by using $0.1 \mathrm{M} \mathrm{HCl}$ solution. This colloidal suspension was then purged with $\mathrm{Ar}$ for $5 \mathrm{~min}$ and bubbled with $\mathrm{H}_{2}$ for $1 \mathrm{~min}$ in order to reduce the Pt precursor. Finally, the reaction vessel was sealed and the solution was left overnight [73]. The synthesized Pt nanoparticles were then characterized by TEM and HRTEM microscopy techniques. The average particle size of the PtNP tetra nanoparticles is $8.5 \mathrm{~nm}$. Surface structure characterization was carried out by adsorbing $\mathrm{Ge}$ and $\mathrm{Bi}$ on a fraction of the nanoparticles [74-76], and the results pointed out that the PtNP tetra nanoparticles have $42 \%$ of (111) sites and a 3\% (100) sites. Therefore, the Pt nanoparticles used in this work have a preferential (111) surface structure.

For the electrochemical measurements, $3 \mu \mathrm{L}$ of a sonicated wa-

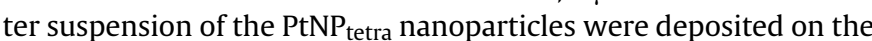
surface of a glassy carbon collector electrode, which was previously mechanically polished with alumina from higher to lower particle sizes and then sonicated and rinsed with ultrapure water [77]. The deposited drop was dried with an Ar atmosphere. The electro-

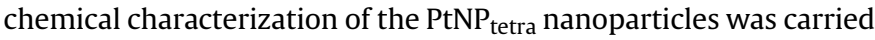
out as previously reported in Refs. [78-80]. The active surface area of the Pt nanoparticles was determined by measuring the charge involved in the hydrogen UPD region, assuming that the total charge after the subtraction of the double layer charging contribution involves $200 \mu \mathrm{C} \mathrm{cm}^{-2}$ in $0.1 \mathrm{M} \mathrm{HClO}_{4}$ [81].

In-situ infrared measurements were carried out in a glass cell with a platinum wire and a reversible hydrogen electrode as counter and reference electrodes, respectively. The spectroelectrochemical cell was coupled with a prismatic $\mathrm{CaF}_{2}$ window labeled at $60^{\circ}$, and the experiments were performed by using a Nexus 8700 (Thermo Scientific) spectrometer equipped with a MCT-A detector and a Veemax (Pike Tech.) reflectance accessory placed in the main chamber. All the spectra were collected with a resolution of $8 \mathrm{~cm}^{-1}$ and are presented in absorbance units (a. u.) as $-\log \left(R / R_{0}\right)$ where $R$ and $R_{0}$ represent the single beam sample and reference reflectivity spectra, respectively. Therefore, positive-going and negative-going bands correspond to the gain and loss of species for the sample spectrum with respect to the reference spectrum. Sets of 100 interferograms were collected at different sample potentials and referred to a reference single beam spectrum collected in the acetonitrile-containing solution at the indicated reference potentials $\left(\mathrm{E}_{\mathrm{ref}}\right)$.

The online mass spectrometry setup used in the monitoring of the produced $\mathrm{CO}_{2}$ during the formic acid oxidation reaction is described in Ref. [82] and examples of its application are presented in Refs. [83-86]. The mass spectrometer consists in a Prisma QMS 200 quadrupole detector (Pfeiffer) detector with a secondary electron multiplier (SEM) operating at a voltage of $2400 \mathrm{~V}$, brought to vacuum with a TMH-071P turbo molecular pump (Pfeiffer) and a Duo 2.5 rotary vane pump (Pfeiffer). The mass spectrometer and the electrochemical cell were connected through a stainless steel tube followed by a PEEK capillary with an inner diameter of $0.57 \mathrm{~mm}$ and an outer diameter of $1.59 \mathrm{~mm}$ with an inlet tip at the end where the reaction products formed at the electrode interface were collected. This inlet tip is made from a Kel-F holder which contains a $0.6 \mathrm{~mm}$ porous Teflon cylinder with an average pore size of $40 \mu \mathrm{m}$. This Teflon membrane is placed very close to the electrode surface, about $10 \mu \mathrm{m}$, by using a micrometer positioning system and a camera. The electrode was contacting the solution in the hanging meniscus configuration in all cases. The pressure inside the mass spectrometer was always lower than $10^{-6}$ mbar during the measurements.

The reagents used for preparing the working solutions were concentrated $\mathrm{HClO}_{4}$ (Merck, for analysis), $\mathrm{HCOOH}$ (Merck, for analysis, 98-100\%) and $\mathrm{CH}_{3} \mathrm{CN}$ (Sigma-Aldrich, anhydrous, 99.8\%). $\mathrm{Ar}$ and $\mathrm{H}_{2}$ (N50, Air Liquide) were also employed. Ultrapure water (Elga PureLab Ultra, $18.2 \mathrm{M} \Omega \mathrm{cm}$ ) was used for glassware cleaning and the preparation of the solutions. The glassware was cleaned in all cases by immersion in an acid $\mathrm{KMnO}_{4}$ solution during at least $12 \mathrm{~h}$ and then rinsed with $\mathrm{H}_{2} \mathrm{O}_{2}$ and $\mathrm{H}_{2} \mathrm{SO}_{4}$ in ultrapure water solution. After that, it was boiled in ultrapure water for 4 times. The inlet tip for the OLEMS measurements was cleaned by immersion in a $0.2 \mathrm{M} \mathrm{K}_{2} \mathrm{Cr}_{2} \mathrm{O}_{7}$ in $2 \mathrm{M} \mathrm{H}_{2} \mathrm{SO}_{4}$ solution and rinsed exhaustively with ultrapure water. The influence of acetonitrile concentration was investigated by successive addition of $\mathrm{CH}_{3} \mathrm{CN}$ in the electrochemical cell and performing the flame-annealing procedure before each measurement in the case of single crystal electrodes or rinsing with ultrapure water the working electrode in the case of PtNP tetra nanoparticles experiments. The current densities for formic acid oxidation measurements are obtained from the geometric area for single-crystal electrodes and from the active area determined as explained above for the platinum nanoparticles. Solutions for in situ infrared measurements were prepared in deuterium oxide, $\mathrm{D}_{2} \mathrm{O}$, in order to avoid interferences from water signals around $1600 \mathrm{~cm}^{-1}$. All experiments were carried out at room temperature.

\section{Results and discussion}

\subsection{Pt(111) and Pt(100)}

\subsubsection{Cyclic voltammetry}

Prior to the study of the effect of acetonitrile towards the formic acid oxidation reaction, the electrode|solution interface in $0.1 \mathrm{M}$ 
$\mathrm{HClO}_{4}$ and different concentrations of $\mathrm{CH}_{3} \mathrm{CN}$ was characterized by means of cyclic voltammetry for both $\mathrm{Pt}(111)$ and $\mathrm{Pt}(100)$ electrodes (Fig. 1). Results are in agreement with those in the literature $[67,68]$. In this work, we present results for higher concentrations of acetonitrile. The voltammetric profiles have the typical characteristics of a partially blocked surface since the hydrogen adsorption charge for the two surfaces is smaller than that measured in the absence of acetonitrile in solution and new peaks appear (Fig. 1). These peaks are related to surface processes of acetonitrile. For $\mathrm{Pt}(111)$, the signals between 0.3 and $0.6 \mathrm{~V}$ have been traditionally attributed to the reduction and reoxidation processes of adsorbed acetonitrile, and the peaks above $0.6 \mathrm{~V}$ would correspond to the coadsorption of $\mathrm{OH}$ species on the acetonitrile modified surface $[67,68]$. However, the reduction peak at ca. $0.45 \mathrm{~V}$ could correspond to the signal of hydroxyl anions desorption modified by adsorbed acetonitrile. In the case of $\mathrm{Pt}(100)$, both oxidation peaks at ca. $0.2 \mathrm{~V}$ and $0.8 \mathrm{~V}$ are related to the redox processes of the adsorbed acetonitrile-related species. In-situ infrared spectroscopy experiments in presence of acetonitrile were also performed (Fig. S1). The spectra are in agreement with the results reported in Ref. [68]. The only difference is that the IR intensities for the Pt(100) surface are similar to those recorded for the $\mathrm{Pt}(111)$ electrode, whereas in the previous work by Morin et al. [68], the Pt(100) exhibit much lower relative intensities. These differences are probably related to the better quality of the $\mathrm{Pt}(100)$ electrode used in the present work. The same wavenumber is observed for the bands on both $\mathrm{Pt}(111)$ and $\mathrm{Pt}(100)$ electrodes, and therefore it is expected that the adsorbed

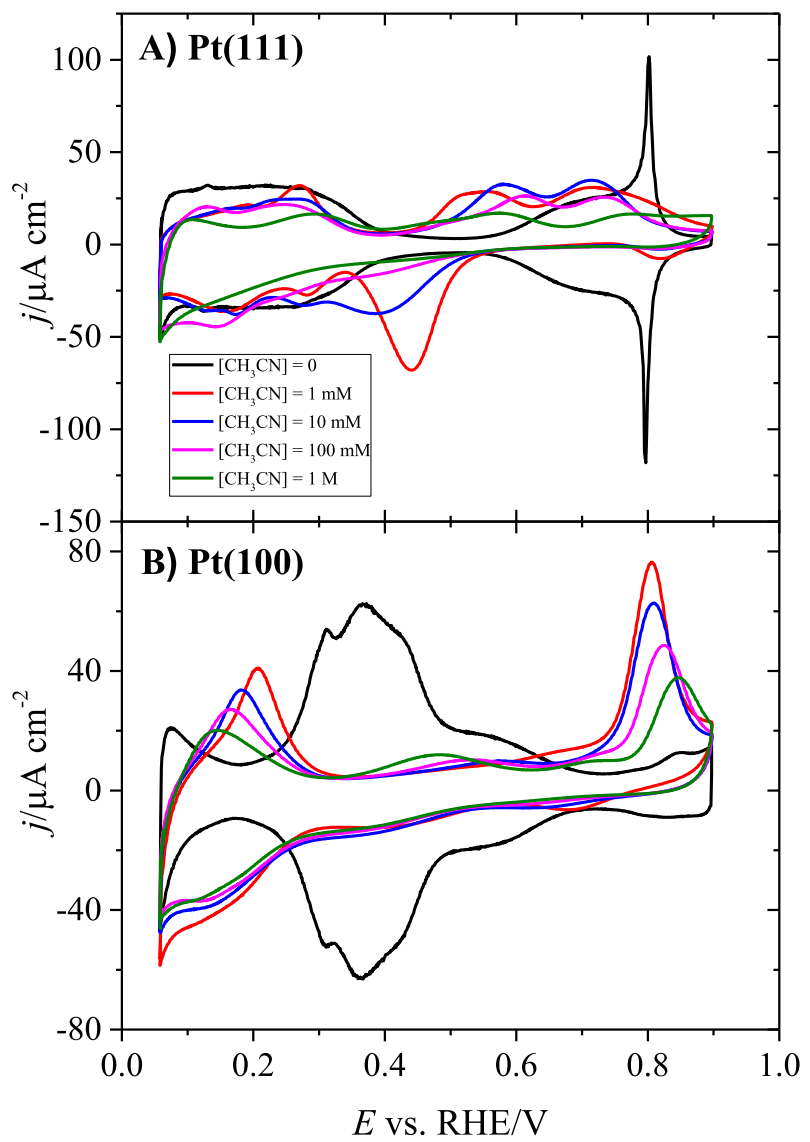

Fig. 1. Voltammetric profiles for $\mathrm{Pt}(111)$ (A) and $\mathrm{Pt}(100)$ (B) in $0.1 \mathrm{M} \mathrm{HClO}_{4}$ and different concentrations of $\mathrm{CH}_{3} \mathrm{CN}$ from $1 \mathrm{mM}$ to $1 \mathrm{M}$. Black lines correspond to the profiles in absence of $\mathrm{CH}_{3} \mathrm{CN}$. Scan rate: $50 \mathrm{mV} \mathrm{s}^{-1}$. Figure shows the second cycles. The immersion potential was 0.1 vs. RHE and the measurements started in the negative direction. Profiles are stable upon cycling. species have the same nature in both cases. From all these results, it is clear that adsorbed acetonitrile or any derived species remains on the surface in the studied potential range. As can be seen in the voltammetry, the sharpness and intensity of the new peaks decrease as the acetonitrile concentration is increased: the reduction peak at $0.45 \mathrm{~V}$ for $\mathrm{Pt}(111)$ becomes broader and moves to more negative potentials as its intensity decreases, while in the case of $\mathrm{Pt}(100)$ the intensity of the oxidation peaks is also reduced. This could be due to oligomerization processes of the adsorbed species that hinders the redox processes [67].

It is important to highlight that the hydrogen adsorption region is far from being totally supressed by acetonitrile in the case of $\mathrm{Pt}(111)$ : while in the absence of $\mathrm{CH}_{3} \mathrm{CN}$ the integrated charge in the $\mathrm{H}_{\mathrm{ads}}$ region is $160 \mu \mathrm{C} \mathrm{cm}^{-2}$, this value is ca. $75 \mu \mathrm{C} \mathrm{cm}^{-2}$ for acetonitrile concentrations $1 \mathrm{mM}$ and $10 \mathrm{mM}$, ca. $70 \mu \mathrm{Ccm}^{-2}$ for $0.1 \mathrm{M}$ and it only decreases drastically to ca. $25 \mu \mathrm{C} \mathrm{cm}^{-2}$ for the highest concentration of $1 \mathrm{M}$. The same behavior was observed previously by Conway et al. [52,67,68], and it points out that adsorbed acetonitrile species never supress completely hydrogen adsorption on $\mathrm{Pt}(111)$ or polycrystalline Pt surfaces even for high acetonitrile concentrations such as $1 \mathrm{M}$. These observations contrast the results in Ref. [66] for glassy carbon electrodes modified with platinum nanoparticles: for $100 \mathrm{ppm}$ of acetonitrile (ca. $2.5 \mathrm{mM}$ ) a complete suppression of the hydrogen adsorption is observed. Since in Ref. [52] a much smaller suppression of $\mathrm{H}_{\mathrm{ads}}$ region is observed for higher concentrations also for polycrystalline surfaces, it should exist some difference between both experimental conditions in Refs. [52,66], e.g., the presence of additional impurities in the work by El-Nagar et al. [66] (apart from acetonitrile) which adsorb on the electrode surface and produce a more effective blocking effect towards hydrogen adsorption. In any case, it is clear that adsorbed acetonitrile always leaves a significant fraction of the surface available for hydrogen co-adsorption on the $\mathrm{Pt}(111)$ electrode. The situation is different for $\mathrm{Pt}(100)$, since in this case the $\mathrm{H}_{\mathrm{ads}}$ region is almost totally suppressed by acetonitrile adsorption even for the lowest concentration of $\mathrm{CH}_{3} \mathrm{CN}$. Hydrogen adsorption and $\mathrm{OH}$ adsorption take place between 0.2 and $0.7 \mathrm{~V}$ on $\mathrm{Pt}(100)$ and in this range practically a double-layer behavior is observed in the presence of acetonitrile. Additionally, the signals related to the small amount of adsorbed hydrogen at $\mathrm{E}<0.2 \mathrm{~V}$ shift towards lower potential values, which is typical behavior of the $\mathrm{Pt}(100)$ electrode when the coverage of the blocking species increases [34]. These results point out that acetonitrile adsorption coverage is very sensitive to the structure orientation since a completely different behavior is observed between the different well-defined structures. As will be shown, this will lead to different electrocatalytic activities towards formic acid oxidation on these surfaces. It is important to bear in mind that it is difficult to carry out a precise calculation of the real coverage of adsorbed acetonitrile in these surfaces because of all the observations explained above. Although the extent of hydrogen suppression on the $\mathrm{Pt}(111)$ and the $\mathrm{Pt}(100)$ electrodes is different, there are always active Pt free sites for formic acid oxidation.

Formic acid oxidation reaction in $0.1 \mathrm{M} \mathrm{HCOOH}$ has been studied on the $\mathrm{Pt}(111)$ and $\mathrm{Pt}(100)$ electrodes for increasing concentrations of $\mathrm{CH}_{3} \mathrm{CN}$, from $1 \mathrm{mM}$ to $1 \mathrm{M}$ (Fig. 2). The results in absence of acetonitrile are in agreement with the results presented in the literature $[16,44,87]$. On $\mathrm{Pt}(100)$ the reaction is inhibited during the positive potential sweep due to the presence of $\mathrm{CO}$, the poison intermediate, formed at low potentials [88]. In the negative-going scan, high oxidation currents are measured since at potentials above $0.8 \mathrm{~V}$ the $\mathrm{CO}$ adlayer is oxidatively stripped. From ca. $0.5 \mathrm{~V}, \mathrm{CO}$ is formed again, giving rise again to an inhibition of the electrochemical activity [88]. On the other hand, on $\operatorname{Pt}(111)$ there is already observable electrocatalytic activity in the positive-going 


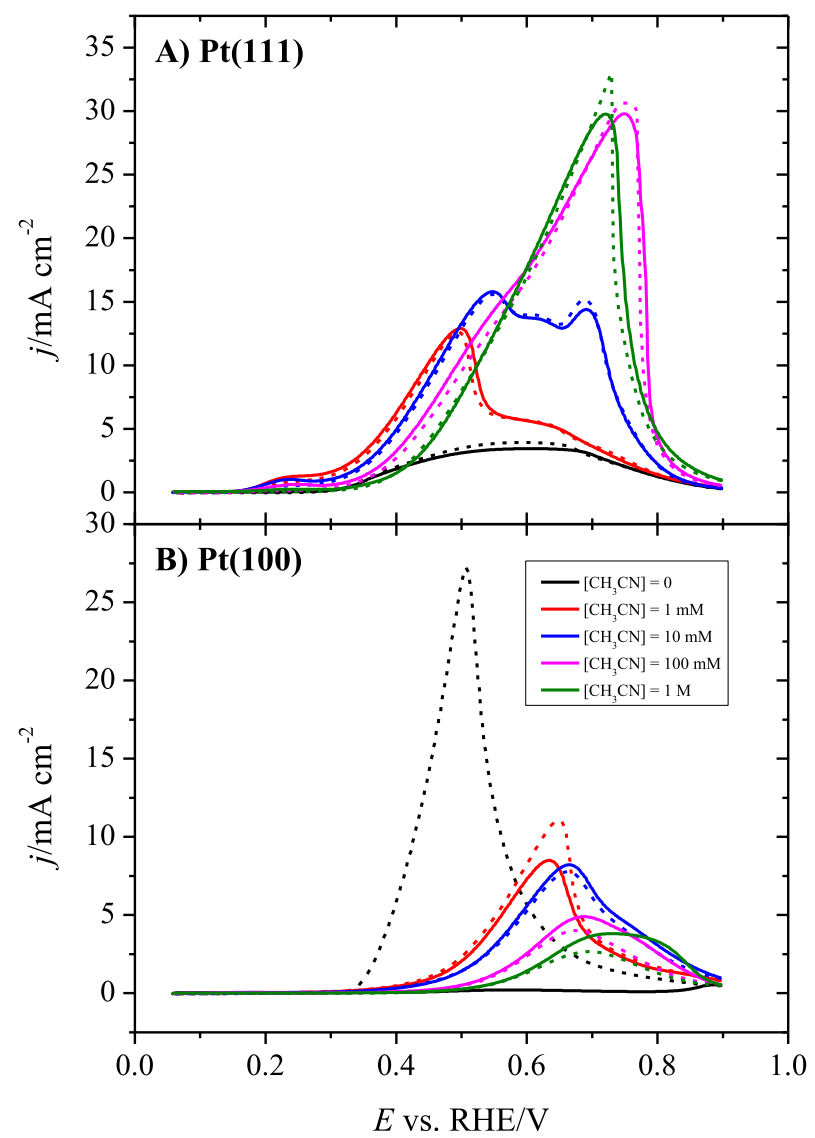

Fig. 2. Voltammetric profiles for the formic acid oxidation reaction on $\operatorname{Pt}(111)(\mathrm{A})$ and $\mathrm{Pt}(100)(\mathrm{B})$ in $0.1 \mathrm{M} \mathrm{HClO}_{4}+0.1 \mathrm{M} \mathrm{HCOOH}$ and different concentrations of acetonitrile. Solid lines: positive-going scans; dashed lines: negative-going scans. Scan rate: $50 \mathrm{mV} \mathrm{s}^{-1}$.

scan, being the onset potential at ca. $0.3 \mathrm{~V}$ and the negative-going scan is very similar with small hysteresis behavior. The small differences are due to the residual formation of $\mathrm{CO}$ on the defect sites located on the real $\mathrm{Pt}(111)$ surface [89]. However, the current densities, in this case, are much lower than in the negative-going scan for $\mathrm{Pt}(100)$, indicating that (100) orientation is more active than (111) toward formic acid oxidation.

When acetonitrile is added to the solution, different behaviors can be observed. In the first place, the onset of the formic acid oxidation reaction on the $\mathrm{Pt}(111)$ electrode is significantly shifted to lower potential values, at ca. $0.15 \mathrm{~V}$ for $1 \mathrm{mM} \mathrm{CH}_{3} \mathrm{CN}$. In addition, there is almost no hysteresis between the positive and negative scan directions when acetonitrile is present (see Fig. S3), indicating that $\mathrm{CO}$ formation at defect sites is negligible during the time scale of the scans. Finally, as the $\mathrm{CH}_{3} \mathrm{CN}$ concentration increases, currents for $\mathrm{E}<0.3 \mathrm{~V}$ diminish, whereas, on the other side, they increase for $\mathrm{E}>0.3 \mathrm{~V}$. The initial conclusion of the voltammetric profiles is that the presence of acetonitrile on the $\mathrm{Pt}(111)$ surface catalyzes the direct oxidation of formic acid.

The behavior of the $\mathrm{Pt}(100)$ electrode is significantly different from that observed for the Pt(111) electrode. First, currents are measured in the positive scan direction at potentials higher than $0.3 \mathrm{~V}$, and the positive and negative-going scans almost overlap. Second, in the negative scan direction, onset potential increases and currents significantly diminishes as the acetonitrile concentration increases. Thus, it can be concluded that for the Pt(100), the only beneficial effect of the presence of acetonitrile on the surface is the diminution of poison formation, $\mathrm{CO}$, as revealed by the increase in currents measured in the positive scan direction when compared to that obtained in absence of acetonitrile. However, there is a significant diminution of the overall currents and an increase of the overpotential. The diminution of the $\mathrm{CO}$ formation can be followed using FTIR experiments (Fig. S2). As can be seen, in the absence of acetonitrile, linear and bridge bonded $\mathrm{CO}$ bands are observed at ca. 2030 and $1870 \mathrm{~cm}^{-1}$, which are absent in the presence of acetonitrile, proving the effect of acetonitrile in the inhibition of the $\mathrm{CO}$ formation.

It was proposed that the formation of adsorbed $\mathrm{CO}$ would need at least three contiguous Pt sites $[48,90]$. In fact, in the DFT proposed mechanism, several Pt sites are required to form CO [15]. Therefore, the diminution of the $\mathrm{CO}$ formation on the $\mathrm{Pt}(100)$ electrode can be associated with the larger ensemble of Pt sites required in the formation of $\mathrm{CO}$ when compared to the direct oxidation. Thus, the occupation of some Pt sites inhibits the formation of $\mathrm{CO}$ poison intermediate but leaving enough sites for the reaction through of the active intermediate and its subsequent oxidation to $\mathrm{CO}_{2}$. Similar results were obtained for adatom modified $\mathrm{Pt}(100)$ electrodes [48] and using cyanide-modified Pt(111) electrodes [91]. However, in the case of $\mathrm{Pt}(100)$, although the presence of acetonitrile inhibits the formation of the poison intermediate, the oxidation currents decrease as the acetonitrile concentration is increased. Therefore, the surface structure dependence of acetonitrile adsorption leads to differences in the formic acid oxidation electrocatalysis. As can be seen in the voltammetric profiles in $0.1 \mathrm{M} \mathrm{HClO}_{4}$ in presence of acetonitrile, the hydrogen adsorption/desorption processes on $\mathrm{Pt}(100)$ are more inhibited in comparison to $\mathrm{Pt}(111)$. This seems to indicate that the acetonitrile coverage on the Pt surface is higher in $\mathrm{Pt}(100)$ than in $\mathrm{Pt}(111)$. These differences would suggest that although acetonitrile can enhance the activity, it is necessary to have also enough free Pt sites in order to have an optimal electroactivity.

Owing to the lower potential onset of the oxidation on the $\mathrm{Pt}(111)$ electrode in presence of acetonitrile, the current response below $0.3 \mathrm{~V}$ for $\mathrm{Pt}(111)$ was investigated in detail. Several cycles up to different upper potentials, $\mathrm{E}_{\mathrm{u}}$, were recorded, (Fig. 3). For $\mathrm{E}_{\mathrm{u}}=0.2 \mathrm{~V}$, the current density values are completely stable during cycling, but when the upper limit is increased to $0.3 \mathrm{~V}$ currents decrease slightly after each cycle. For $\mathrm{E}_{\mathrm{u}}=0.4 \mathrm{~V}$ this decrease is more evident. These results point out that below $0.2 \mathrm{~V}$ the formic acid oxidation is taking place via the active intermediate with no $\mathrm{CO}$ formation, but if the upper potential limit is increased poison generation takes place to some extent. The current diminution after each cycle points out that some $\mathrm{CO}$ could be formed in the presence of acetonitrile. It should be highlighted that $\mathrm{CO}$ formation is kinetically hindered on the Pt(111) electrode [15] and the observed $\mathrm{CO}$ formation on real Pt(111) electrodes should be connected to the presence of defects on the surface [89]. For unmodified electrodes, there is a direct relationship between the $\mathrm{CO}$ formation rate and the oxidation rate through the active intermediate [15]. However, in the presence of acetonitrile, a lower formation of $\mathrm{CO}$ is expected similarly to the observed behavior for electrodes modified by adatoms [48] or cyanide adlayers [90]. In any case, results shown in Fig. 3 points out that small amounts of $\mathrm{CO}$ are formed and $\mathrm{CO}$ can accumulate on the platinum surface when $\mathrm{CO}$ oxidation potentials are not reached.

On the other hand, the increase in the oxidation currents for the $\mathrm{Pt}(111)$ electrode also needs an explanation. Since CO formation is hindered on the $\mathrm{Pt}(111)$ surface, the reason of this enhancement should be different from a simple third-body effect. Formate can be adsorbed in the monodentate and bidentate forms, being this bidentate form the most stable [15] and can be detected by ATRSEIRAS [11,12]. However, the relevant species for the oxidation is the monodentate form. The stabilization of the monodentate form, 

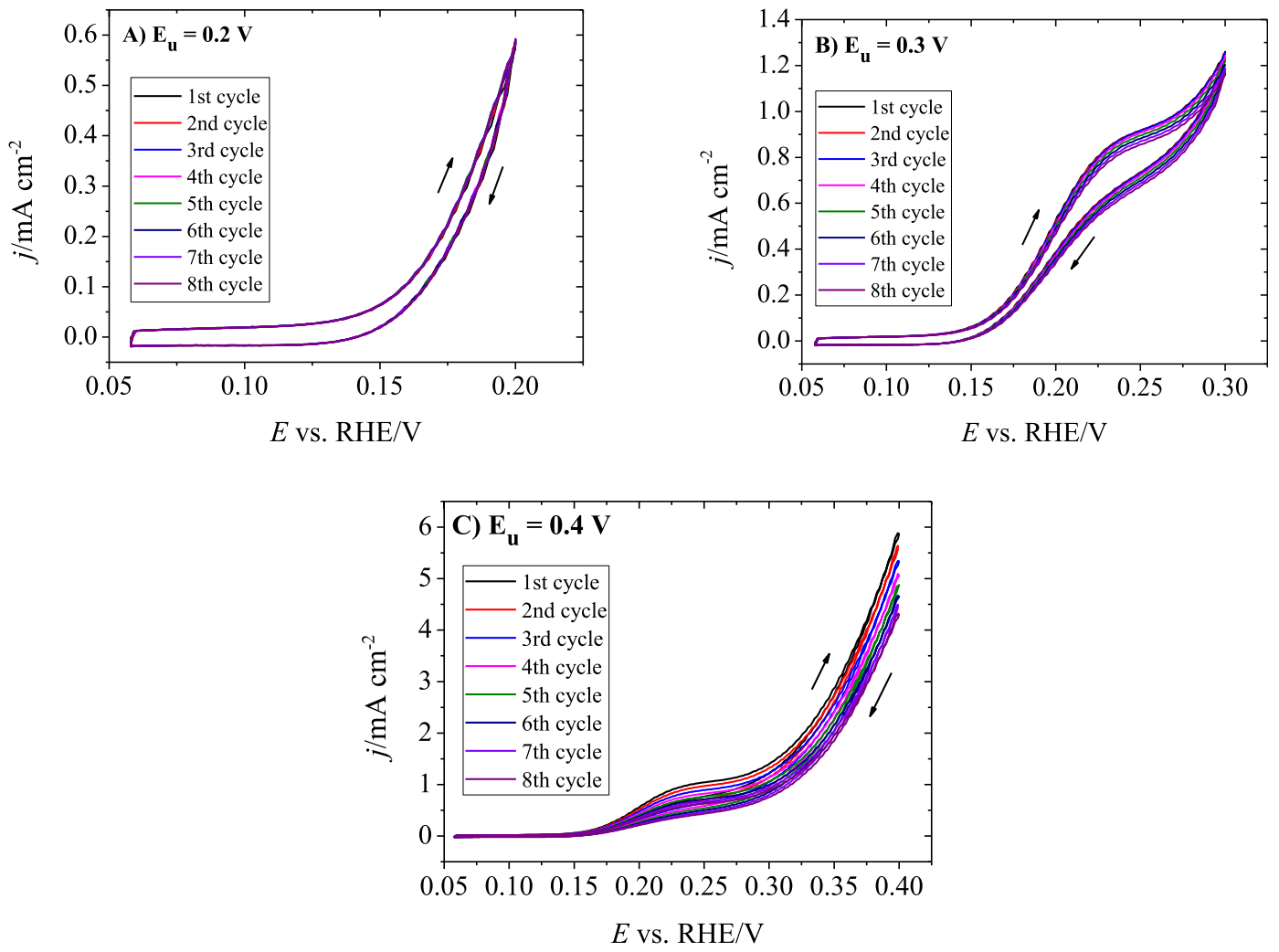

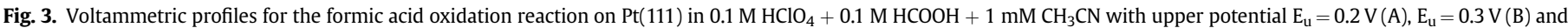
$\mathrm{E}_{\mathrm{u}}=0.4 \mathrm{~V}(\mathrm{C})$. Scan rate: $50 \mathrm{mV} \mathrm{s}^{-1}$.

which leads to an effective electrocatalysis of the reaction, can take place by the presence of adatoms or other adsorbed species on the surface, as demonstrated by DFT calculations [15]. These adsorbed species make difficult the transformation of the monodentate form into the most stable bidentate form. This mechanism could be used to explain the present results: adjacent adsorbed acetonitrile would favor the adsorption of formate in the monodentate form and obstruct the rotation of the adsorbed formate to form the stable but inactive form in a similar way to the observed for adsorbed species $[2,15]$. In fact, this transformation is inhibited when the monodentate adsorbed formate is surrounded by adsorbed bidentate formate. In this sense, the role in the mechanism of adsorbed acetonitrile can be the same as that observed for adsorbed bidentate formate. The adsorption in this favourable configuration (the monodentate form) allows the easy cleavage of the $\mathrm{C}-\mathrm{H}$ bond giving rise $\mathrm{CO}_{2}$ at higher reaction rates [15].

\subsubsection{On-line mass spectrometry}

Although oxidation of formic acid to $\mathrm{CO}_{2}$ is the most probable reaction occurring during the voltammogram, other possible reactions, such as the oxidation of acetonitrile in the presence of formic acid or oxidative reactions between formic acid and acetonitrile cannot be discarded a priori. In order to determine if the oxidation currents correspond to the oxidation of formic acid to $\mathrm{CO}_{2}$, the formation of $\mathrm{CO}_{2}$ product during the formic acid oxidation was followed by using the on-line mass spectrometry (OLEMS) technique. In this way, it is possible to investigate at which potentials the reaction is taken place via the direct oxidation to $\mathrm{CO}_{2}$. A similar study was reported by Vidal-Iglesias et al. for the investigation of formic acid oxidation on $\mathrm{Pt}(111)$ and $\mathrm{Pt}(100)$ electrodes modified by different coverages of Pd [42]. In our experiment, the selected scan rate for the cyclic voltammetry is $1 \mathrm{mV} \mathrm{s}^{-1}$ in order to have well-resolved the mass signals from the mass spectrometer $[85,86]$. The quantitative calibration of the apparatus is difficult with the present setup since the collected amount of $\mathrm{CO}_{2}$ depends on the distance between the electrode and the inlet tip, which change from experiment to experiment since meniscus height is slightly different. For this reason, two different experiments with the same oxidation currents for formic acid oxidation can lead to different $\mathrm{CO}_{2}$ mass currents.

Figs. 4 and 5 show the oxidation currents and the $\mathrm{m} / \mathrm{z}=44$ currents, simultaneously recorded for the $\operatorname{Pt}(111)$ and $\operatorname{Pt}(100)$ electrodes, respectively, during the triangular scan potential at $1 \mathrm{mV} \mathrm{s}^{-1}$. No other mass signals (aside from $\mathrm{m} / \mathrm{z}=28$ related to the fragmentation of $\mathrm{CO}_{2}$ ) are observed, which indicates that the only product is $\mathrm{CO}_{2}$. The differences between the voltammetric profiles of Fig. 2 and those presented here are only due to the different scan rate and the same trend can be observed for both basal planes (see Fig. S4). It is important to highlight that the hysteresis between the positive and negative scan directions increases due to the lower scan rate. CO formation reaction takes place in the unmodified surfaces at potentials below $0.4 \mathrm{~V}$ [89] and therefore, the lower the scan rate is, the higher coverage of $\mathrm{CO}$ is obtained.

When the oxidation currents and those associated with $\mathrm{m} /$ $\mathrm{z}=44$ are compared, an excellent correlation between them can be observed. It can be concluded that measured current densities are due to only the formic acid oxidation to $\mathrm{CO}_{2}$ via both the active intermediate or $\mathrm{CO}$ oxidation at high potentials. It is important to remark that the oxidation current observed at ca. $0.15 \mathrm{~V}$ on $\mathrm{Pt}(111)$ also gives rise to the detection of $\mathrm{CO}_{2}$ product (Fig. S5). This observation, in combination with the results shown in Fig. 3A, corroborates that the oxidation of formic acid via the active intermediate can take place at more negative potentials in the presence of acetonitrile. 

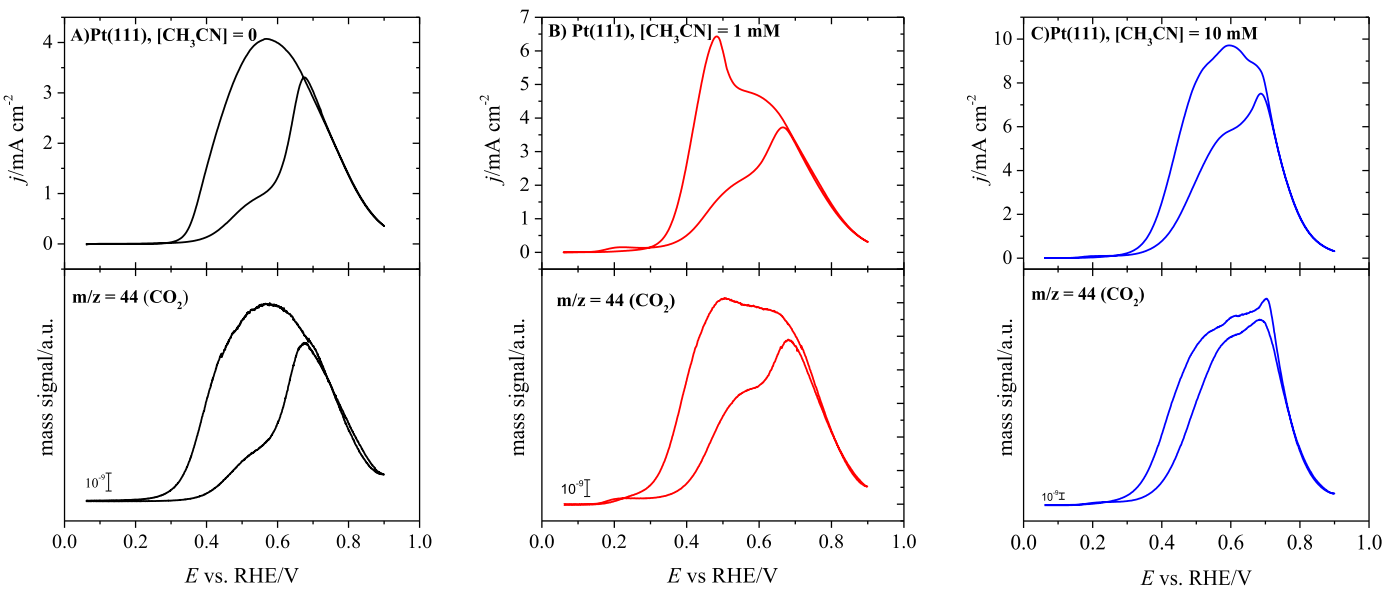

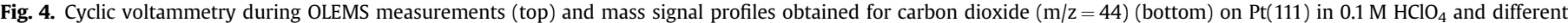
$\mathrm{CH}_{3} \mathrm{CN}$ concentrations. Scan rate: $1 \mathrm{mV} \mathrm{s}^{-1}$
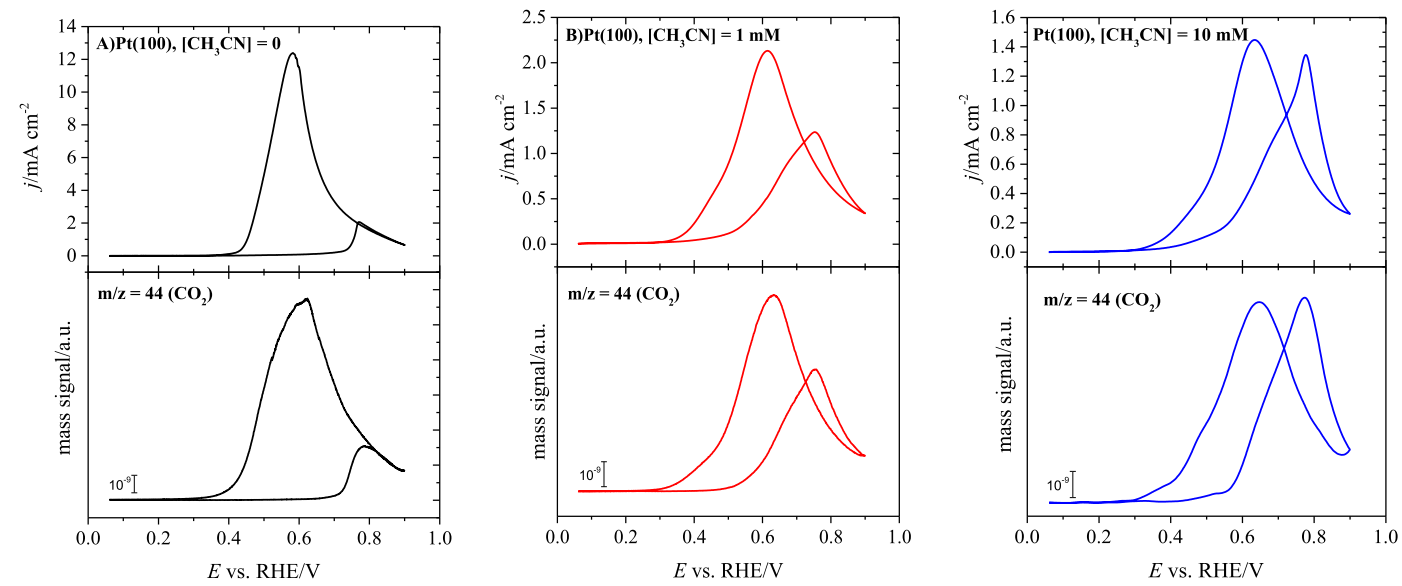

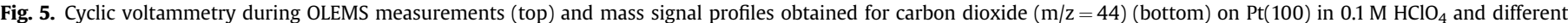
$\mathrm{CH}_{3} \mathrm{CN}$ concentrations. Scan rate: $1 \mathrm{mV} \mathrm{s}^{-1}$.

\subsubsection{Chronoamperometric studies}

In order to investigate the long-term performance of the reaction under these conditions, chronoamperometric measurements have been carried out in presence of $1 \mathrm{mM}$ and $10 \mathrm{mM} \mathrm{CH}_{3} \mathrm{CN}$ for both $\mathrm{Pt}(111)$ and $\mathrm{Pt}(100)$ electrodes, and the results have been compared to the situation without acetonitrile (Fig. 6).

Chronoamperometric experiments can provide information about the electrocatalytic improvement at any specific potential. In this case, the electrode was immersed in the solution at a controlled potential of $0.1 \mathrm{~V}$, then a potential pulse was performed in order to keep the electrode at $0.9 \mathrm{~V}$ during $3 \mathrm{~s}$ for removing the previously formed $\mathrm{CO}$, and after that another potential pulse was carried out to maintain the electrode at $0.45 \mathrm{~V}$ for $20 \mathrm{~min}$. On Pt(111), there is a significant increase of the oxidation currents, not only after the pulse but also after $20 \mathrm{~min}$. The current density decreases slowly during the chronoamperometric measurement. This fact agrees with the behavior mentioned in section 3.1.1: at $0.45 \mathrm{~V}$ formation of $\mathrm{CO}$ at a slow rate is taking place. This slow diminution in the current highlights the role of the side reaction path on the overall observed reactivity. Although the reaction rate through the direct path is at least two orders of magnitude higher than that measured for the $\mathrm{CO}$ formation path [15], the progressive accumulation of adsorbed CO on the surface leads to the diminution of the currents.

On the other hand, measured currents for the $\mathrm{Pt}(100)$ electrode are almost negligible after $500 \mathrm{~s}$ after the pulse. It can be observed from Fig. $6 \mathrm{~B}$ that the higher the acetonitrile concentration is, the slower the poisoning rate becomes. However, as the high acetonitrile coverage also blocks Pt sites for formic acid oxidation, the current density values for $\mathrm{Pt}(100)$ are much smaller than on $\mathrm{Pt}(111)$. In fact, it can be seen that although the poisoning rate for $\mathrm{Pt}(100)$ is slower in presence of $\mathrm{CH}_{3} \mathrm{CN}$, the initial current at the beginning of the pulse is higher in the absence of acetonitrile. In conclusion, the chronoamperometric measurements confirm the observations made in the previous sections, and they point out that the improvement of $\mathrm{Pt}(111)$ performance in presence of acetonitrile for formic acid oxidation can be still observed after long periods of time.

\subsection{PtNP tetra nanoparticles}

Finally, formic acid oxidation on platinum nanoparticles was studied in order to investigate the effects of acetonitrile on a more suitable catalyst material for practical applications in fuel cells. The use of well-defined surfaces and preferentially oriented nanoparticles allows the direct comparison with the theoretical studies to clarify the reactivity of the different surface sites, and this helps to understand the behavior of the polycrystalline materials used in a practical device. Following this idea, the formic acid oxidation in 


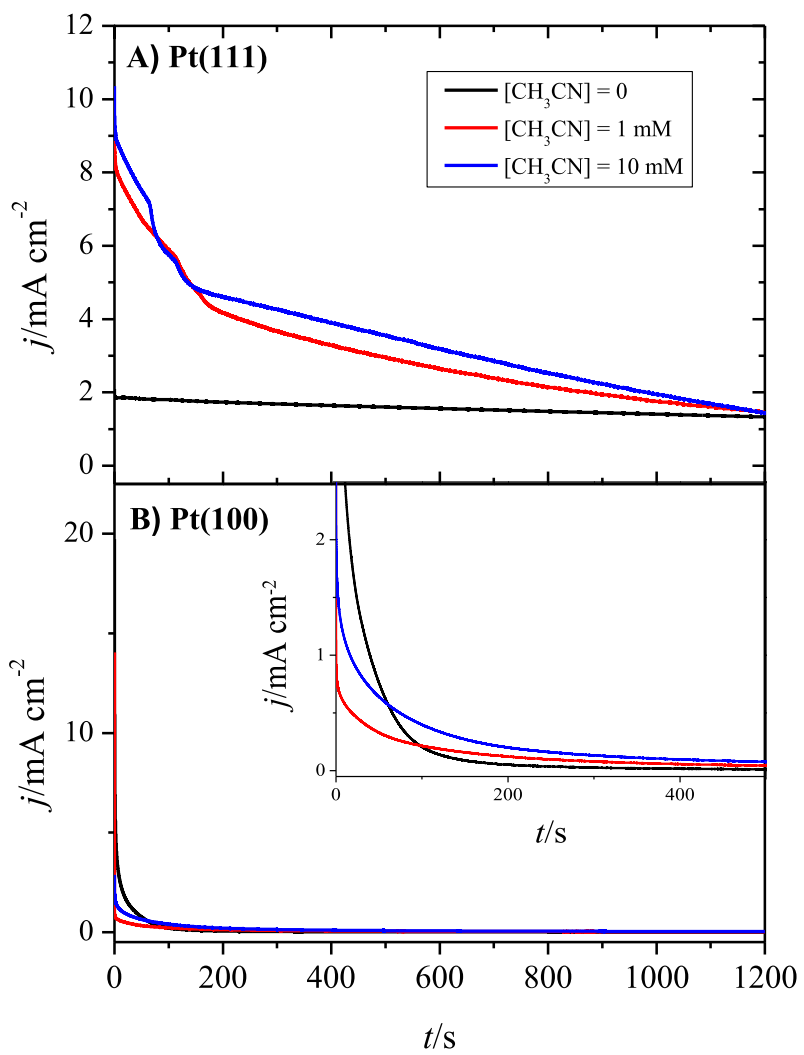

Fig. 6. Chronoamperometric measurements at $\mathrm{E}=0.45 \mathrm{~V}$ vs. $\mathrm{RHE}$ for $\mathrm{Pt}(111)(\mathrm{A})$ and $\mathrm{Pt}(100)$ in $0.1 \mathrm{M} \mathrm{HClO}_{4}$ and different concentrations of $\mathrm{CH}_{3} \mathrm{CN}$. Inset: Zoom in for $\mathrm{Pt}(100)$ up to $500 \mathrm{~s}$.

presence of acetonitrile on shape-controlled Pt nanoparticles is investigated. The chosen Pt nanoparticles have a preferential (111) surface structure since the higher oxidation currents in presence of acetonitrile were obtained for $\mathrm{Pt}(111)$. The voltammetric profile of the PtNPtetra nanoparticles in $0.1 \mathrm{M} \mathrm{HClO}_{4}$ used is shown in the inset of Fig. 7, and it is comparable to the previous one reported by Chen et al. for the same type of nanoparticles in the same

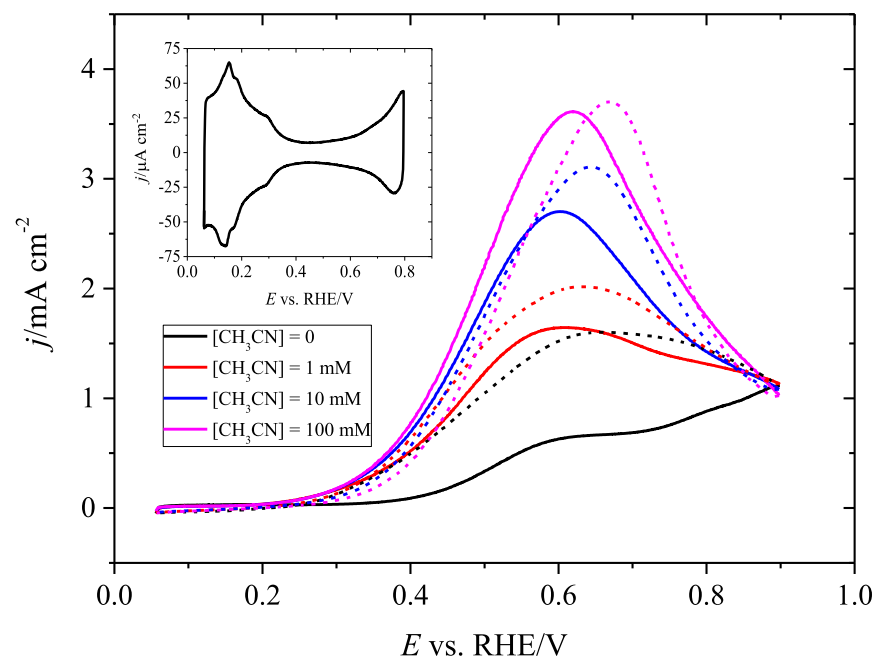

Fig. 7. Cyclic voltammetry for the formic acid oxidation reaction on the PtNPtetra nanoparticles in $\mathrm{HClO}_{4} 0.1 \mathrm{M}$ and different concentrations of $\mathrm{CH}_{3} \mathrm{CN}$. Scan rate: $50 \mathrm{mV} \mathrm{s}^{-1}$. Inset: $\mathrm{CV}$ for the $\mathrm{PtNP}_{\text {tetra }}$ nanoparticles in $\mathrm{HClO}_{4}$ in the absence of $\mathrm{CH}_{3} \mathrm{CN}$. Scan rate: $50 \mathrm{mV} \mathrm{s}^{-1}$. conditions [81]. Results for the dependence of the formic acid oxidation on acetonitrile concentration show the same behavior observed for the Pt(111) single crystal electrode (Fig. 7): higher oxidations currents are observed at more negative potentials as the acetonitrile concentration is increased, and the maximum oxidation current value is also improved. For a potential value of $0.6 \mathrm{~V}$, the maximum oxidation density current in the case of $0.1 \mathrm{M} \mathrm{CH}_{3} \mathrm{CN}$ in the negative-going sweep is increased by a factor of 2.0 in comparison to the case in absence of acetonitrile, while in the positive-going sweep it is enhanced by a factor of 5.6.

Chronoamperometric studies were also performed in order to test the activity of the PtNPtetra nanoparticles in presence of acetonitrile in more similar conditions to practical fuel cell applications (Fig. 8). In this case, current density values in the presence of acetonitrile are much higher during the first seconds of the experiment, but the current decay is faster than in the case of Pt(111) (Fig. 6). When a cyclic voltammetry experiment is performed after the chronoamperometric measurement on PtNP tetra nanoparticles in the presence of acetonitrile, the positive-going sweep in the first cycle is very similar to the cyclic voltammogram in absence of acetonitrile (see Fig. S6), implying that $\mathrm{CO}$ is accumulated on the surface. The catalytic behavior due to the presence of acetonitrile is not recovered until the adsorbed $\mathrm{CO}$ formed during the chronoamperometric measurement is oxidized at high potentials. This is probably because PtNPtetra nanoparticles have domains with different orientations which are more sensitive to $\mathrm{CO}$ poisoning. This competition of formed $\mathrm{CO}$ for the Pt is reported here for the first time because it was not reported in the previous work by El-Nagar et al. with acetonitrile [66]. This could be due to the presence of other impurities different than acetonitrile that adsorb strongly to the platinum surface, which supports the fact that hydrogen adsorption region is more inhibited, or to the use of sulphuric acid as supporting electrolyte instead of perchloric acid. Sulphate anions can adsorb specifically to the surface and they can interact with adsorbed acetonitrile molecules.

\section{Conclusions}

The present work points out that surface modification with organic molecules can lead to an enhancing the electrocatalytic activity of metal surfaces towards the oxidation of small organic molecules in a similar way to the effect of metallic adatoms. In this case, an enhancement of the formic acid oxidation in acidic media

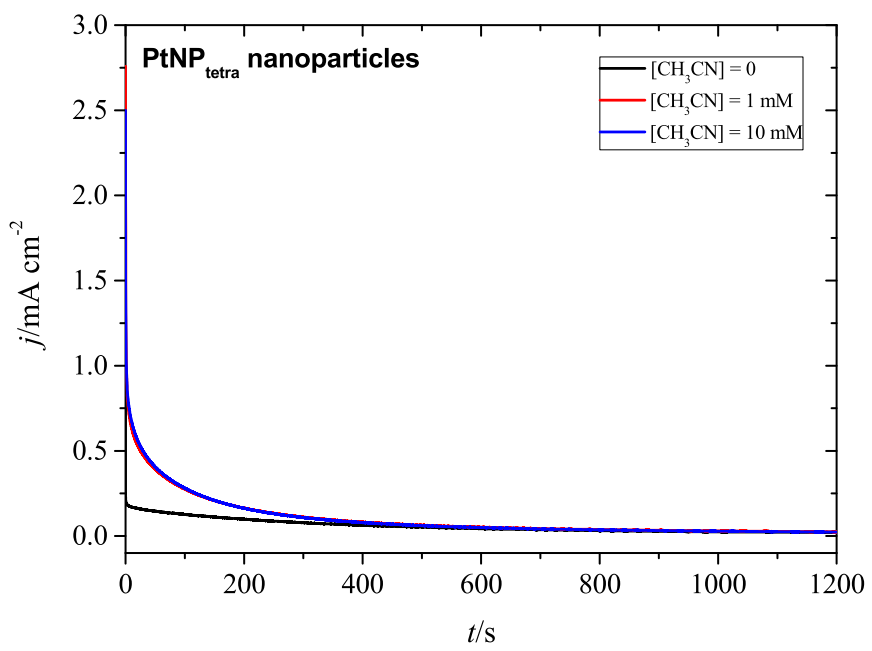

Fig. 8. Chronoamperometries at $\mathrm{E}=0.45 \mathrm{~V}$ vs. RHE for the $\mathrm{PtNP}_{\text {tetra }}$ nanoparticles in $0.1 \mathrm{M} \mathrm{HClO}_{4}$ and different concentrations of $\mathrm{CH}_{3} \mathrm{CN}$. 
has been observed in the presence of acetonitrile on well-defined Pt surfaces, both single crystal electrodes, and shape-controlled nanoparticles. The results show that the electrocatalytic effect on the formic acid oxidation carried out by acetonitrile is structure sensitive. In the case of Pt(111), oxidation currents can be observed at ca. $0.15 \mathrm{~V}$ vs. RHE when acetonitrile its present, while in the case of supporting electrolyte only the onset potential is at ca. $0.3 \mathrm{~V}$ vs RHE. In addition, maximum current values are also higher as the $\mathrm{CH}_{3} \mathrm{CN}$ concentration is increased. A similar behavior is observed for the tetrahedral and octahedral Pt nanoparticles. For Pt(100), there is a drastic reduction of the hysteresis usually observed for this orientation, since oxidation currents can be measured at much more negative potentials in the positive-going sweep.

The promoting effect of acetonitrile toward the formic acid oxidation is mainly due to the ability of adsorbed acetonitrile to block Pt sites inhibiting the formation of $\mathrm{CO}$ intermediate and enhancing the oxidation via the direct path. Results suggest that the catalysis mechanism is similar to that observed for adatoms, in which the presence of the modifier facilitates the adsorption of formic acid (or formate) in the right configuration so that the $\mathrm{C}-\mathrm{H}$ bond can be easily cleaved yielding a $\mathrm{CO}_{2}$ molecule [2,15,47]. In the light of the results with the well-defined platinum surfaces, it can be proposed that the onset potential for the formic acid oxidation on Pt electrodes is more negative in the presence of acetonitrile because the monodentate mode of formic acid is favored on (111) sites at low potentials when adjacent acetonitrile molecules are present. This monodentate form gives rise the direct oxidation of formic acid to $\mathrm{CO}_{2}$. At more positive potentials, some $\mathrm{CO}$ is formed on both (111) and (100) sites, but the formation rate is slower than in the absence of acetonitrile. By comparing the results for $\mathrm{Pt}(111)$ and $\mathrm{Pt}(100)$ it can be deduced that a certain number of free Pt sites in combination with sites occupied by acetonitrile are necessary in order to have a better electrocatalytic enhancement, and the number of free sites is lower on $\operatorname{Pt}(100)$ because of the higher coverage of acetonitrile in this case.

The electrocatalytic effect favoring the active intermediate path has been confirmed by using the OLEMS technique since there is a good correspondence between the cyclic voltammetry and the measured mass signals for $\mathrm{CO}_{2}$. In addition, OLEMS measurements in combination with potentiostatic measurements also indicated that below $0.3 \mathrm{~V}$ the formic acid oxidation is taking place almost totally through the active intermediate. Finally, chronoamperometric studies show that the $\mathrm{CO}$ poisoning rate is slower in the presence of acetonitrile and current values are higher even at long times on $\mathrm{Pt}(111)$.

In summary, the enhancement of formic acid oxidation activity by adsorbed acetonitrile on Pt surface is mainly due to two effects: i) a third-body effect, especially on the $\mathrm{Pt}(100)$ orientation, since currents in the positive-going scan are remarkedly increased and in-situ infrared measurements in the presence of both acetonitrile and formic acid point out that much less $\mathrm{CO}$ is formed in the presence of acetonitrile; ii) a promotion of the active intermediate path as indicated by the increase of current densities on Pt(111) and the apparition of oxidation currents at ca. $0.15 \mathrm{~V}$, potentials at which OLEMS measurements confirm that $\mathrm{CO}_{2}$ is being formed. Chronoamperometric measurements reflect the promoting effect by acetonitrile lasts for several minutes without an important current decrease. Experiments for preferentially-oriented $\mathrm{Pt}$ nanoparticles show that the enhancement is extrapolated to more practical electrodes but with some differences since these surfaces are far from ideality.

The number of works in the literature using an organic molecule for surface modification in order to achieve electrocatalytic improvements is scarce. Here we presented a systematic study by employing well-defined surface which can open the door to more similar studies using not only metallic adlayers but also others of different nature.

\section{Acknowledgements}

This work has been financially supported by the MINECO-FEDER (Spain) through project CTQ2016-76221-P. V. B-M thankfully acknowledges to MINECO the award of a predoctoral grant (BES2014-068176, project CTQ2013-44803-P) and a student stay grant (EEBB-I-16-11656). S-G. acknowledges financial support from Vicerrectorado de Investigación y Transferencia de Conocimiento of the University of Alicante (UATALENTO16-02).

\section{Appendix A. Supplementary data}

Supplementary data to this article can be found online at https://doi.org/10.1016/j.electacta.2018.11.016.

\section{References}

[1] M.T.M. Koper, S.C.S. Lai, E. Herrero, Mechanisms of the oxidation of carbon monoxide and small organic molecules at metal electrodes, in: M.T.M. Koper (Ed.), Fuel Cell Catalysis, a Surface Science Approach, John Wiley \& Sons, Inc, Hoboken, NJ, 2009, pp. 159-208.

[2] A. Ferre-Vilaplana, J.V. Perales-Rondon, J.M. Feliu, E. Herrero, Understanding the effect of the adatoms in the formic acid oxidation mechanism on $\mathrm{Pt}(111)$ electrodes, ACS Catal. 5 (2015) 645-654.

[3] A. Capon, R. Parsons, The oxidation of formic acid at noble metal electrodes: I. Review of previous work, J. Electroanal. Chem. 44 (1973) 1-7.

[4] A. Capon, R. Parsons, The oxidation of formic acid on noble metal electrodes: II. A comparison of the behaviour of pure electrodes, J. Electroanal. Chem. 44 (1973) 239-254.

[5] A. Capon, R. Parsons, The oxidation of formic acid at noble metal electrodes Part III. Intermediates and mechanism on platinum electrodes, J. Electroanal. Chem. 45 (1973) 205-231.

[6] B. Beden, A. Bewick, C. Lamy, A comparative study of formic acid adsorption on a platinum electrode by both electrochemical and emirs techniques, J. Electroanal. Chem. 150 (1983) 505-511.

[7] K. Kunimatsu, Infrared spectroscopic study of methanol and formic acid adsorbates on a platinum electrode: Part I. Comparison of the infrared absorption intensities of linear $\mathrm{CO}(\mathrm{a})$ derived from $\mathrm{CO}, \mathrm{CH}_{3} \mathrm{OH}$ and $\mathrm{HCOOH}$, J. Electroanal. Chem. 213 (1986) 149-157.

[8] S.G. Sun, J. Clavilier, A. Bewick, The mechanism of electrocatalytic oxidation of formic acid on Pt (100) and Pt (111) in sulphuric acid solution: an emirs study, J. Electroanal. Chem. 240 (1988) 147-159.

[9] S.C. Chang, M.J. Weaver, In situ infrared spectroscopy of CO adsorbed at ordered Pt(100)- aqueous interfaces : double layer effects upon the adsorbate binding geometry, J. Phys. Chem. 94 (1990) 5095.

[10] J. Willsau, J. Heitbaum, Analysis of adsorbed intermediates and determination of surface potential shifts by DEMS, Electrochim. Acta 31 (1986) 943-948.

[11] Y.X. Chen, A. Miki, S. Ye, H. Sakai, M. Osawa, Formate, an active intermediate for direct oxidation of methanol on Pt electrode, J. Am. Chem. Soc. 125 (2003) $3680-3681$

[12] G. Samjeske, A. Miki, S. Ye, M. Osawa, Mechanistic study of electrocatalytic oxidation of formic acid at platinum in acidic solution by time-resolved surface-enhanced infrared absorption spectroscopy, J. Phys. Chem. B 110 (2006) 16559-16566.

[13] Y.X. Chen, S. Ye, M. Heinen, Z. Jusys, M. Osawa, R.J. Behm, Application of in-situ attenuated total reflection-Fourier transform infrared spectroscopy for the understanding of complex reaction mechanism and kinetics: formic acid oxidation on a Pt film electrode at elevated temperatures, J. Phys. Chem. B 110 (2006) 9534-9544.

[14] Y.X. Chen, M. Heinen, Z. Jusys, R.J. Behm, Bridge-bonded formate: active intermediate or spectator species in formic acid oxidation on a Pt film electrode? Langmuir 22 (2006) 10399-10408.

[15] A. Ferre-Vilaplana, J.V. Perales-Rondon, C. Buso-Rogero, J.M. Feliu, E. Herrero, Formic acid oxidation on platinum electrodes: a detailed mechanism supported by experiments and calculations on well-defined surfaces, J. Mater. Chem. 5 (2017) 21773-21784.

[16] J. Clavilier, R. Parsons, R. Durand, C. Lamy, J.M. Leger, Formic acid oxidation on single crystal platinum electrodes. Comparison with polycrystalline platinum, J. Electroanal. Chem. 124 (1981) 321-326.

[17] S. Motoo, N. Furuya, Electrochemistry of platinum single crystal surfaces : Part II. Structural effect on formic acid oxidation and poison formation on Pt (111), (100) and (110), J. Electroanal. Chem. 184 (1985) 303-316.

[18] R.R. Adžić, A.V. Tripković, V.B. Vesšović, Structural effects in electrocatalysis: oxidation of formic acid and hydrogen adsorption on platinum single-crystal stepped surfaces, J. Electroanal. Chem. Interfacial Electrochem. 204 (1986) $329-341$. 
[19] V. Climent, J.M. Feliu, Surface Electrochemistry with Pt Single-Crystal Electrodes, Nanopatterned and Nanoparticle-modified Electrodes, Wiley, 2017.

[20] J.M. Feliu, E. Herrero, V. Climent, Electrocatalytic properties of stepped surfaces, in: E. Santos, W. Schmickler (Eds.), Catalysis in Electrochemistry, John Wiley \& Sons, Inc., Hoboken, 2011, pp. 127-163.

[21] V. Grozovski, F.J. Vidal-Iglesias, E. Herrero, J.M. Feliu, Adsorption of formate and its role as intermediate in formic acid oxidation on platinum electrodes, ChemPhysChem 12 (2011) 1641-1644.

[22] J.V. Perales-Rondon, E. Herrero, J.M. Feliu, Effects of the anion adsorption and $\mathrm{pH}$ on the formic acid oxidation reaction on $\mathrm{Pt}(111)$ electrodes, Electrochim. Acta 140 (2014) 511-517.

[23] J.V. Perales-Rondón, S. Brimaud, J. Solla-Gullón, E. Herrero, R. Jürgen Behm, J.M. Feliu, Further insights into the formic acid oxidation mechanism on platinum: pH and anion adsorption effects, Electrochim. Acta 180 (2015) 479-485.

[24] R. Parsons, T. Vandernoot, The oxidation of small organic molecules: a survey of recent fuel cell related research, J. Electroanal. Chem. 257 (1988) 9-45.

[25] R.I. Masel, Principles of Adsorption and Reaction on Solid Surfaces, John Wiley \& Sons, Inc., New York, 1996.

[26] T.J. Schmidt, H.A. Gasteiger, R.J. Behm, Methanol electrooxidation on a colloidal PtRu-alloy fuel-cell catalyst, Electrochem. Commun. 1 (1999) 1-4.

[27] F. Matsumoto, C. Roychowdhury, F.J. DiSalvo, H.D. Abruna, Electrocatalytic activity of ordered intermetallic PtPb nanoparticles prepared by borohydride reduction toward formic acid oxidation, J. Electrochem. Soc. 155 (2008) B148-B154.

[28] C. Roychowdhury, F. Matsumoto, V.B. Zeldovich, S.C. Warren, P.F. Mutolo, M. Ballesteros, U. Wiesner, H.D. Abruña, F.J. Disalvo, Synthesis, characterization, and electrocatalytic activity of PtBi and $\mathrm{PtPb}$ nanoparticles prepared by borohydride reduction in methanol, Chem. Mater. 18 (2006) 3365-3372.

[29] L.R. Alden, D.K. Han, F. Matsumoto, H.D. Abruña, F.J. DiSalvo, Intermetallic $\mathrm{PtPb}$ nanoparticles prepared by sodium naphthalide reduction of metalorganic precursors: electrocatalytic oxidation of formic acid, Chem. Mater. 18 (2006) 5591-5596.

[30] C. Roychowdhury, F. Matsumoto, P.F. Mutolo, H.D. Abruna, F.J. DiSalvo, Synthesis, characterization, and electrocatalytic activity of PtBi nanoparticles prepared by the polyol process, Chem. Mater. 17 (2005) 5871-5876.

[31] N. Cantillo, J. Solla-Gullón, E. Herrero, C. Sanchez, Ethanol Electrooxidation on PtSnNi/C Nanoparticles Prepared in Water-in-oil Microemulsion, 2011, pp. 1307-1316.

[32] V. Climent, N. García-Araez, J.M. Feliu, Clues for the molecular-level understanding of electrocatalysis on single-crystal platinum surfaces modified by pblock Adatoms, in: M.T.M. Koper (Ed.), Fuel Cells Catalysis. A Surface Science Approach, John Wiley \& Sons, Inc., Hoboken, New Jersey, 2009, pp. 209-244.

[33] E. Herrero, A. Fernández-Vega, J.M. Feliu, A. Aldaz, Poison formation reaction from formic acid and methanol on Pt(111) electrodes modified by irreversibly adsorbed Bi and as, J. Electroanal. Chem. 350 (1993) 73-88.

[34] E. Herrero, J.M. Feliu, A. Aldaz, Poison formation reaction from formic acid on Pt(100) electrodes modified by irreversibly adsorbed bismuth and antimony, J. Electroanal. Chem. 368 (1994) 101-108.

[35] M.J. Llorca, E. Herrero, J.M. Feliu, A. Aldaz, Formic acid oxidation on Pt(111) electrodes modified by irreversibly adsorbed selenium, J. Electroanal. Chem. 373 (1994) 217-225.

[36] E. Herrero, M.J. Llorca, J.M. Feliu, A. Aldaz, Oxidation of formic acid on Pt(111) electrodes modified by irreversibly adsorbed tellurium, J. Electroanal. Chem. 394 (1995) 161-167.

[37] V. Climent, E. Herrero, J.M. Feliu, Electrocatalysis of formic acid and CO oxidation on antimony-modified Pt(111) electrodes, Electrochim. Acta 44 (1998) 1403-1414.

[38] M.D. Maciá, E. Herrero, J.M. Feliu, A. Aldaz, Formic acid self-poisoning on bismuth-modified Pt(755) and Pt(775) electrodes, Electrochem. Commun. 1 (1999) 87-89.

[39] M.D. Maciá, E. Herrero, J.M. Feliu, A. Aldaz, Formic acid self-poisoning on bismuth-modified stepped electrodes, J. Electroanal. Chem. 500 (2001) 498-509.

[40] M.D. Maciá, E. Herrero, J.M. Feliu, Formic acid self-poisoning on adatommodified stepped electrodes, Electrochim. Acta 47 (2002) 3653-3661.

[41] M.D. Maciá, E. Herrero, J.M. Feliu, Formic acid oxidation on Bi-Pt(111) electrode in perchloric acid media. A kinetic study, J. Electroanal. Chem. 554 (2003) 25-34

[42] F.J. Vidal-Iglesias, J. Solla-Gullón, E. Herrero, A. Aldaz, J.M. Feliu, Formic acid oxidation on Pd-modified Pt(100) and Pt(111) electrodes: a DEMS study, J. Appl. Electrochem. 36 (2006) 1207-1214.

[43] C. Buso-Rogero, J.V. Perales-Rondon, M.J.S. Farias, F.J. Vidal-Iglesias, J. SollaGullon, E. Herrero, J.M. Feliu, Formic acid electrooxidation on thalliumdecorated shape-controlled platinum nanoparticles: an improvement in electrocatalytic activity, Phys. Chem. Chem. Phys. 16 (2014) 13616-13624.

[44] A. Boronat-Gonzalez, E. Herrero, J.M. Feliu, Fundamental aspects of $\mathrm{HCOOH}$ oxidation at platinum single crystal surfaces with basal orientations and modified by irreversibly adsorbed adatoms, J. Solid State Electrochem. 18 (2014) 1181-1193.

[45] C. Busó-Rogero, J. Solla-Gullón, F.J. Vidal-Iglesias, E. Herrero, J.M. Feliu, Adatom modified shape-controlled platinum nanoparticles towards ethanol oxidation, Electrochim. Acta 196 (2016) 270-279.

[46] A.C. Garcia, Y.Y. Birdja, G. Tremiliosi-Filho, M.T.M. Koper, Glycerol electrooxidation on bismuth-modified platinum single crystals, J. Catal. 346 (2017)
$117-124$.

47] J.V. Perales-Rondon, A. Ferre-Vilaplana, J.M. Feliu, E. Herrero, Oxidation mechanism of formic acid on the bismuth adatom-modified Pt(111) surface, J. Am. Chem. Soc. 136 (2014) 13110-13113.

[48] E. Leiva, T. Iwasita, E. Herrero, J.M. Feliu, Effect of adatoms in the electrocatalysis of $\mathrm{HCOOH}$ oxidation. A theoretical model, Langmuir 13 (1997) 6287-6293.

[49] J. Clavilier, A. Fernández-Vega, J.M. Feliu, A. Aldaz, Heterogeneous electrocatalysis on well defined platinum surfaces modified by controlled amounts of irreversibly adsorbed adatoms. 1. Formic-acid oxidation on the Pt (111) - Bi system, J. Electroanal. Chem. 258 (1989) 89-100.

[50] A. Fernández-Vega, J.M. Feliu, A. Aldaz, J. Clavilier, Heterogeneous electrocatalysis on well-defined platinum surfaces modified by controlled amounts of irreversibly adsorbed adatoms: Part IV. Formic acid oxidation on the Pt(111)-As system, J. Electroanal. Chem. 305 (1991) 229-240.

[51] C. Buso-Rogero, S. Brimaud, J. Solla-Gullon, F.J. Vidal-Iglesias, E. Herrero, R.J. Behm, J.M. Feliu, Ethanol oxidation on shape-controlled platinum nanoparticles at different pHs: a combined in situ IR spectroscopy and online mass spectrometry study, J. Electroanal. Chem. 763 (2016) 116-124.

[52] H. Angerstein-Kozlowska, B. Macdougall, B.E. Conway, Electrochemisorption and reactivity of nitriles at platinum electrodes and the anodic $\mathrm{H}$ desorption effect, J. Electroanal. Chem. 39 (1972) 287-313.

[53] R.W. Murray, Chemically modified electrodes, Accounts Chem. Res. 13 (1980) 135-141.

[54] D.E. Sauer, R.L. Borup, E.M. Stuve, Electrocatalysis of formic acid and carbon monoxide with probe adlayers of carbon and ethylidine on $\mathrm{Pt}(111)$, in: G. Jerkiewicz, M.P. Soriaga, K. Uosaki, A. Wieckowski (Eds.), Solid-liquid Electrochemical Interfaces, American Chemical Society, 1997, pp. 283-296.

[55] R. Gómez, J. Solla-Gullón, J.M. Pérez, A. Aldaz, Surface-enhanced Raman spectroscopy study of ethylene adsorbed on a Pt electrode decorated with pt nanoparticles, ChemPhysChem 6 (2005) 2017-2021.

[56] H. Angerstein-Kozlowska, B. Macdouga, B.E. Conway, Origin of activation effects of acetonitrile and mercury in electrocatalytic oxidation of formic-acid, J. Electrochem. Soc. 120 (1973) 756-766.

[57] S. Wasmus, W. Vielstich, Influence of acetonitrile, dimethylsulphoxide and lead on the electro-oxidation of small organic molecules: an on-line mass spectroscopy study, J. Electroanal. Chem. 359 (1993) 175-191.

[58] S. Wasmus, W. Vielstich, The electro-oxidation of formic acid, formamide and dimethylformamide in aqueous acid solution. A comparative study using online MS, Electrochim. Acta 38 (1993) 185-189.

[59] S. Wasmus, D.A. Tryk, W. Vielstich, Electrochemical-behavior of nitromethane and its influence on the electro-oxidation of formic acid: an on-line MS study, J. Electroanal. Chem. 377 (1994) 205-214.

[60] I. Ledezma-Yanez, O. Díaz-Morales, M.C. Figueiredo, M.T.M. Koper, Hydrogen oxidation and hydrogen evolution on a platinum electrode in acetonitrile, ChemElectroChem 2 (2015) 1612-1622.

[61] I. Ledezma-Yanez, W.D.Z. Wallace, P. Sebastián-Pascual, V. Climent, J.M. Feliu M.T.M. Koper, Interfacial water reorganization as a pH-dependent descriptor of the hydrogen evolution rate on platinum electrodes, Nature Energy 2 (2017) 17031-17037.

[62] J. Solla-Gullon, R. Gomez, A. Aldaz, J.M. Perez, A combination of SERS and electrochemistry in Pt nanoparticle electrocatalysis: promotion of formic acid oxidation by ethylidyne, Electrochem. Commun. 10 (2008) 319-322.

[63] J. Solla-Gullón, F.J. Vidal-Iglesias, J.M. Pérez, A. Aldaz, Alkylidynes-modified Pt nanoparticles: a spectroelectrochemical (SERS) and electrocatalytic study, Electrochim. Acta 54 (2009) 6971-6977.

[64] G.A. El-Nagar, A.M. Mohammad, M.S. El-Deab, T. Ohsaka, B.E. El-Anadouli, Acrylonitrile-contamination induced enhancement of formic acid electrooxidation at platinum nanoparticles modified glassy carbon electrodes, J. Power Sources 265 (2014) 57-61.

[65] M.S. El-Deab, A.M. Mohammad, G.A. El-Nagar, B.E. El-Anadouli, Impurities contributing to catalysis: enhanced electro-oxidation of formic acid at Pt/GC electrodes in the presence of vinyl acetate, J. Phys. Chem. C 118 (2014) 22457-22464.

[66] G.A. El-Nagar, M.S. El-Deab, A.M. Mohammad, B.E. El-Anadouli, Promoting effect of hydrocarbon impurities on the electro-oxidation of formic acid at Pt nanoparticles modified GC electrodes, Electrochim. Acta 180 (2015) 268-279.

[67] S. Morin, B.E. Conway, Surface structure dependence of reactive chemisorption of acetonitrile on single-crystal Pt surfaces, J. Electroanal. Chem. 376 (1994) 135-150.

[68] S. Morin, B.E. Conway, G.J. Edens, M.J. Weaver, The reactive chemisorption of acetonitrile on $\mathrm{Pt}(111)$ and $\mathrm{Pt}(100)$ electrodes as examined by in situ infrared spectroscopy, J. Electroanal. Chem. 421 (1997) 213-220.

[69] C. Korzeniewski, V. Climent, J.M. Feliu, Electrochemistry at platinum single crystal electrodes, in: A.J. Bard, C. Zoski (Eds.), Electroanalytical Chemistry: Series of Advances, CRC Press, Boca Raton, 2012, pp. 75-169.

[70] J. Clavilier, D. Armand, S.G. Sun, M. Petit, Electrochemical adsorption behaviour of platinum stepped surfaces in sulphuric acid solutions, J. Electroanal Chem. 205 (1986) 267-277.

[71] E. Herrero, J.M. Orts, A. Aldaz, J.M. Feliu, Scanning tunneling microscopy and electrochemical study of the surface structure of $\operatorname{Pt}(10,10,9)$ and $\operatorname{Pt}(11,10,10)$ electrodes prepared under different cooling conditions, Surf. Sci. 440 (1999) 259-270.

[72] T.S. Ahmadi, Z.L. Wang, T.C. Green, A. Henglein, M.A. El-Sayed, Shapecontrolled synthesis of colloidal platinum nanoparticles, Science 272 (1996) 
1924-1926.

[73] J. Solla-Gullón, FJ. Vidal-Iglesias, A. López-Cudero, E. Garnier, J.M. Feliu, A. Aldaz, Shape-dependent electrocatalysis: methanol and formic acid electrooxidation on preferentially oriented Pt nanoparticles, Phys. Chem. Chem. Phys. 10 (2008) 3689-3698.

[74] J. Solla-Gullón, F.J. Vidal-Iglesias, P. Rodríguez, E. Herrero, J.M. Feliu, J. Clavilier A. Aldaz, In situ surface characterization of preferentially oriented platinum nanoparticles by using electrochemical structure sensitive adsorption reactions, J. Phys. Chem. B 108 (2004) 13573-13575.

[75] P. Rodríguez, E. Herrero, J. Solla-Gullón, F.J. Vidal-Iglesias, A. Aldaz, J.M. Feliu, Electrochemical characterization of irreversibly adsorbed germanium on platinum stepped surfaces vicinal to Pt(100), Electrochim. Acta 50 (2005) $3111-3121$

[76] P. Rodríguez, J. Solla-Gullón, F.J. Vidal-Iglesias, E. Herrero, A. Aldaz, J.M. Feliu, Determination of (111) ordered domains on platinum electrodes by irreversible adsorption of bismuth, Anal. Chem. 77 (2005) 5317-5323.

[77] A. López-Cudero, J. Solla-Gullón, E. Herrero, A. Aldaz, J.M. Feliu, CO electrooxidation on carbon supported platinum nanoparticles: effect of aggregation, J. Electroanal. Chem. 644 (2010) 117-126.

[78] J. Solla-Gullón, V. Montiel, A. Aldaz, J. Clavilier, Electrochemical characterization of platinum nanoparticles prepared by microemulsion: how to clean them without loss of crystalline surface structure, J. Electroanal. Chem. 491 (2000) 69-77.

[79] J. Solla-Gullón, A. Rodes, V. Montiel, A. Aldaz, J. Clavilier, Electrochemical characterisation of platinum-palladium nanoparticles prepared in a water-inoil microemulsion, J. Electroanal. Chem. 554 (2003) 273-284.

[80] J. Solla-Gullón, V. Montiel, A. Aldaz, J. Clavilier, Synthesis and electrochemica decontamination of platinum-palladium nanoparticles prepared by water-inoil microemulsion, J. Electrochem. Soc. 150 (2003) E104-E109.

81] O.S. Chen, J. Solla-Gullon, S.G. Sun, J.M. Feliu, The potential of zero total charge of Pt nanoparticles and polycrystalline electrodes with different surface structure the role of anion adsorption in fundamental electrocatalysis,
Electrochim. Acta 55 (2010) 7982-7994.

[82] A.H. Wonders, T.H.M. Housmans, V. Rosca, M.T.M. Koper, On-line mass spectrometry system for measurements at single-crystal electrodes in hanging meniscus configuration, J. Appl. Electrochem. 36 (2006) 1215-1221.

[83] T.H.M. Housmans, A.H. Wonders, M.T.M. Koper, Structure sensitivity of methanol electrooxidation pathways on Platinum: an on-line electrochemical mass spectrometry study, J. Phys. Chem. B 110 (2006) 10021-10031.

[84] V. Rosca, M.T.M. Koper, Electrocatalytic oxidation of hydrazine on platinum electrodes in alkaline solutions, Electrochim. Acta 53 (2008) 5199-5205.

[85] M. Duca, V. Kavvadia, P. Rodriguez, S.C.S. Lai, T. Hoogenboom, M.T.M. Koper, New insights into the mechanism of nitrite reduction on a platinum electrode, J. Electroanal. Chem. 649 (2010) 59-68.

[86] E. Pérez-Gallent, M.C. Figueiredo, I. Katsounaros, M.T.M. Koper, Electrocatalytic reduction of Nitrate on Copper single crystals in acidic and alkaline solutions, Electrochim. Acta 227 (2017) 77-84.

[87] J.V. Perales-Rondón, E. Herrero, J.M. Feliu, Effects of the anion adsorption and $\mathrm{pH}$ on the formic acid oxidation reaction on Pt(111) electrodes, Electrochim. Acta 140 (2014) 511-517.

[88] V. Grozovski, V. Climent, E. Herrero, J.M. Feliu, Intrinsic activity and poisoning rate for $\mathrm{HCOOH}$ oxidation at Pt(100) and vicinal surfaces containing monoatomic (111) steps, ChemPhysChem 10 (2009) 1922-1926.

[89] V. Grozovski, V. Climent, E. Herrero, J.M. Feliu, Intrinsic activity and poisoning rate for $\mathrm{HCOOH}$ oxidation on platinum stepped surfaces, Phys. Chem. Chem. Phys. 12 (2010) 8822-8831.

[90] A. Cuesta, At least three contiguous atoms are necessary for CO formation during methanol electrooxidation on platinum, J. Am. Chem. Soc. 128 (2006) 13332-13333.

[91] A. Cuesta, M. Escudero, B. Lanova, H. Baltruschat, Cyclic voltammetry, FTIRS, and DEMS study of the electrooxidation of carbon monoxide, formic acid, and methanol on cyanide-modified Pt(111) electrodes, Langmuir 25 (2009) 6500-6507. 